\title{
Changes in growth of pristine boreal North American forests from 1950 to 2005 driven by landscape demographics and species traits
}

\author{
M. P. Girardin ${ }^{1}$, X. J. Guo ${ }^{1}$, P. Y. Bernier ${ }^{1}$, F. Raulier ${ }^{2}$, and S. Gauthier ${ }^{1}$ \\ ${ }^{1}$ Natural Resources Canada, Canadian Forest Service, Laurentian Forestry Centre, 1055 du P.E.P.S, P.O. Box 10380, Stn. \\ Sainte-Foy, Quebec, QC, G1V 4C7, Canada \\ ${ }^{2}$ Faculté de foresterie et de géomatique, Université Laval, Quebec, QC, G1V 0A6, Canada
}

Correspondence to: M. P. Girardin (martin.girardin@rncan.gc.ca)

Received: 1 November 2011 - Published in Biogeosciences Discuss.: 23 January 2012

Revised: 10 May 2012 - Accepted: 18 May 2012 - Published: 11 July 2012

\begin{abstract}
In spite of the many factors that are occurring and known for positively affecting the growth of forests, some boreal forests across North America have recently felt the adverse impacts of environmental changes. Knowledge of causes for productivity declines in North American boreal forests remains limited, and this is owed to the large spatial and temporal scales involved, and the many plant processes affected. Here, the response of pristine eastern boreal North American (PEBNA) forests to ongoing climatic changes is examined using in situ data, community ecology statistics, and species-specific model simulations of carbon exchanges forced by contemporary climatic data. To examine trends in forest growth, we used a recently acquired collection of tree-ring width data from 252 sample plots distributed in PEBNA forests dominated by black spruce (Picea mariana [Mill.] B.S.P.) and jack pine (Pinus banksiana Lamb.). Results of linear trend analysis on the tree growth data highlight a dominating forest growth decline in overmature forests (age $>120$ years) from 1950 to 2005. In contrast, improving growth conditions are seen in jack pine and mature (70-120 years) black spruce stands. Multivariate analysis of climate and growth relationships suggests that responses of PEBNA forests to climate are dependent on demographic and species traits via their mediation of temperature and water stress constraints. In support of this hypothesis, the simulation experiment suggests that in old-growth black spruce stands the benefit to growth brought on by a longer growing season may have been low in comparison with the increasing moisture stress and respiration losses caused by warmer summer temperatures. Predicted increases in wildfire frequency in PEBNA forests will likely enhance the positive response of
\end{abstract}

landscape-level forest growth to climate change by shifting the forest distribution to younger age classes while also enhancing the jack pine component.

\section{Introduction}

Rising atmospheric carbon dioxide $\left(\mathrm{CO}_{2}\right)$ concentration, lengthening of the growing season due to climate warming, nitrogen deposition, and changes in forest management have resulted in an increase in mean pan-Arctic vegetation production by $0.34 \%$ per year from 1983 to 2005 (Zhang et al., 2008). The "greening" of vegetation was more important in the pan-taiga forest $(0.50 \%$ per year) than in the panboreal forest ( $0.20 \%$ per year) (Zhang et al., 2008). While increasing vegetation production occurred for broadly continuous regions in Eurasia, it occurred in a fragmented way across North America (Hicke et al., 2002; Nemani et al., 2003; Wang et al., 2011; De Jong et al., 2012). In spite of the many factors that are occurring and known for positively affecting the growth of boreal forests, some forests across North America have felt the adverse impacts of environmental changes. Declines in forest production during the past three decades were notably reported in spruce forests in interior Alaska (Hicke et al., 2002; Beck et al., 2011) and much of the eastern boreal forests (Hicke et al., 2002; Girardin et al., 2011a). This paradigm between improving environmental conditions and declining production may occur as suitable climate envelopes of well-established species rapidly shift away and give rise to the onset of biome shifts (Michaelian et al., 2011; Beck et al., 2011), and as changes in biomass

Published by Copernicus Publications on behalf of the European Geosciences Union. 
burning and disturbance regimes initiate new forest structures that constrain accelerating rates of potential carbon assimilation (Metsaranta et al., 2010; Girardin et al., 2011a).

Knowledge of causes of productivity declines in North American boreal forests remains limited. Direct in situ monitoring of all factors that may contribute to forest responses is challenging owing to the large spatial and temporal scales involved, and the many plant processes affected (Medlyn et al., 2011). Model simulations of vegetation productivity changes have been carried out but fail to capture declines in vegetation productivity in some environmental settings (e.g. Beck et al., 2011). Furthermore, many of these models have coarse parameterization that ignores distinctive species traits or the effect of environmental gradients on species responses to changing environmental conditions (Schwalm et al., 2010; Medlyn et al., 2011). Understanding the sources of spatial variation in productivity changes is an important requirement for projecting how vegetation growth will respond to new environmental conditions.

In this article, we examine trends in growth of pristine eastern boreal North American (PEBNA) forests from 1950 to 2005 using in situ data. We generated hypotheses on potential climate drivers using community ecology statistics, and provide a mechanistic understanding of the potential processes involved using species-specific model simulations of carbon exchanges forced by contemporary climatic data. To examine trends in forest growth, we used a recently acquired collection of tree-ring width data from 252 sample plots distributed in PEBNA forests dominated by black spruce (Picea mariana [Mill.] B.S.P.) and jack pine (Pinus banksiana Lamb.). All tree-ring data were processed using a procedure that aims at preserving low-frequency trends. As for the modeling experimentation, we used a leaf-level model to simulate high-frequency responses of carbon fluxes to climate variability, and a canopy-level model, based on the Physiological Principle Predicting Growth (3PG) model (Landsberg and Waring, 1997) adjusted to the aggregated leaf-level results, to simulate yearly plot-level net primary production (NPP) for the period encompassing the tree-ring data (i.e. 1950-2005).

\section{Materials and methods}

\subsection{Study area}

The PEBNA forests under study encompass $76^{\circ} \mathrm{W}$ to $70^{\circ} \mathrm{W}$ and $51^{\circ} \mathrm{N}$ and $53^{\circ} \mathrm{N}$ (Supplement Fig. S1) and have been excluded from harvesting (Ministère des Ressources naturelles du Québec, 2000). These forests, occupied by mature to overmature stands (age $>70$ years) in a proportion of $\sim 53 \%$, play a vital role in maintaining ecological attributes for large migratory wildlife and act as an important terrestrial carbon sink, storing $\sim 13 \mathrm{~g}$ of carbon (C) $\mathrm{m}^{-2} \mathrm{yr}^{-1}$ (data from Chen et al., 2003). Therein, natural dynamics are still shaping land- scape diversity and influencing biochemical cycles. The surrounding region is known as the Boreal Shield and is underlain by an ancient granite bed. Vegetation in the southern part of the study area belongs to the coniferous Sprucefeather moss (Picea mariana-moss) bioclimatic domain; the northern vegetation belongs to the coniferous Spruce-lichen (Picea mariana-lichen) bioclimatic domain (Saucier et al., 1998). Climate is classified as humid mid-boreal.

\subsection{Forest inventories and tree-ring data}

Data on forest composition, stand age (oldest trees approximated by tree-ring count), soil texture, aspect and slope were obtained from a database of $400 \mathrm{~m}^{2}$ circular sample plots established by the ministère des Ressources naturelles et de la Faune du Québec in 2005 and 2006 (Program d'inventaire écoforestier nordique: Létourneau et al., 2008). A total of 284 sample plots were preselected for our work; only those plots that had all the available information necessary for modeling experiments were used. Aboveground biomass was estimated for each stem within a plot using measured diameter at breast height and the species-specific tree biomass equations of Lambert et al. (2005). Values were summed to obtain estimates of plot-level total aboveground biomass. We assumed a $50 \%$ biomass-to-carbon conversion factor. Stand attributes were used later on as input to the stand-level process-based model.

As part of the sampling program, disks were collected from up to 10 living trees and saplings within each plot. The collected samples were sanded and cross-dated (Yamaguchi, 1991), and each annual ring was measured using a VELMEX measuring system interfaced with a computer or a WinDENDRO flatbed scanner. All of the measuring was done at the Laurentian Forestry Centre, Québec. For each measurement series, cross-dating and measurements were statistically verified using the program COFECHA (Holmes, 1983), which calculates cross-correlation to a lag of 10 years between each individual standardized measurement series and a reference chronology. This verification procedure was done at individual and multiple-plot $\left(\sim 1.0^{\circ} \times 1.0^{\circ}\right.$ grids $)$ levels. The ringwidth measurement series were rescaled using a power transformation method, and detrended using negative exponential modeling (Supplement and Fig. 1) in order to eliminate noise caused by site- and biological-related effects (e.g. competition, self-thinning and aging) while preserving the variance in low frequencies (Cook and Peters, 1997). The standardized series were then averaged using a bi-weight robust mean at the plot level to create tree growth index (TGI) time series. Departures from the mean TGI are interpreted as departures due to climate variability or some other non-biologically induced forcing. Our study did not include growth data on young ( 0 to 20 years) and immature (20 to 70 years) stands owing to difficulties in recovering long-term growth changes in short TGI time series (see Cook et al., 1995). 


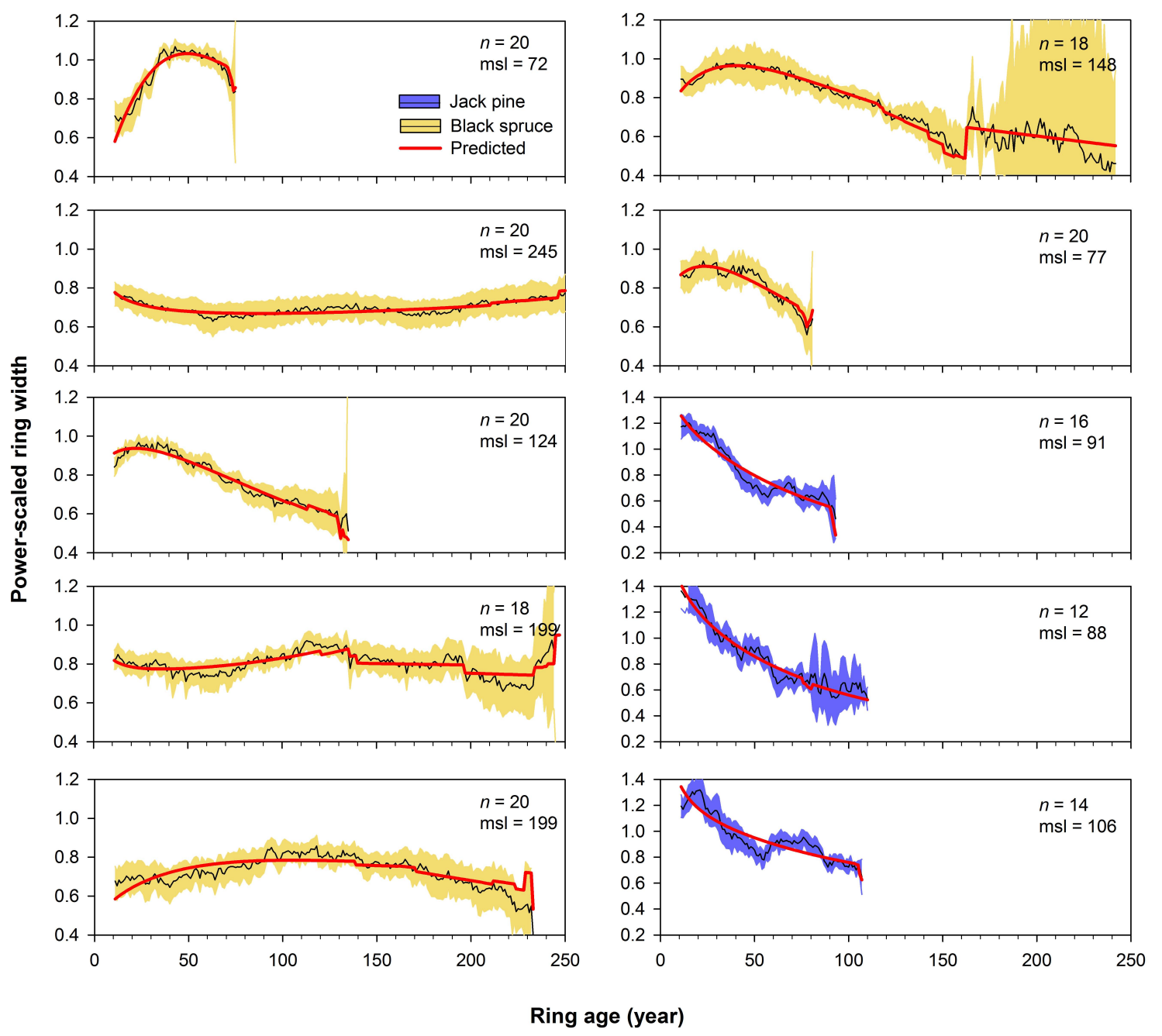

Fig. 1. Plot-level black spruce and jack pine sample-average tree-ring width versus ring age for a subset of the 252 plots under study. The tree-ring width measurement series were rescaled using a power transformation method for elimination of heteroscedasticity. Shaded area shows $90 \%$ confidence interval associated with the sample-average. Total number of samples ( $n$ ) (divide by two for the number of trees) and mean sample length ( $\mathrm{msl}$ in years) are indicated. Also plotted are the sample-average exponential fits used in the detrending procedure of the tree-ring width measurement series.

\subsection{Climate data}

A major difficulty encountered in this study was the absence of meteorological stations across the study area running over a period of time encompassing that of the TGI time series. This climate data limitation imposes major challenges for exploring forest growth and climate relationships and for simulation experimentation. To circumvent this issue, monthly means of daily minimum and maximum temperatures, total monthly precipitation, and water content in the 1 to $2 \mathrm{~m}$ of soil (Fan and van den Dool, 2004) for the region, encompassing $76^{\circ} \mathrm{W}$ to $70^{\circ} \mathrm{W}, 51^{\circ} \mathrm{N}$ to $53^{\circ} \mathrm{N}$ and the period of 1950-2005, were obtained from the Twentieth Century Reanalysis (20CR) project (Compo et al., 2011). A "reanalysis" is a climate model simulation of the past that includes data assimilation of historical observations. The use of a climate model allows interpolation between observations in a physically consistent manner rather than a statistical one. The 20CR makes use of an Ensemble Kalman Filter data assimilation system, an atmosphere-land model (NCEP) with interpolated monthly sea-surface temperature and sea-ice concentration fields as prescribed boundary conditions, and surface and sea level pressure reports and observations for assimilation. The reanalysis data should not be assumed to have the status of real observations; the quality of data depends on the availability of pressure observations. A pointwise correlation between the gridded 20CR data and statistically interpolated Climate Research Unit TS2.1 gridded data (Mitchell and Jones, 2005) showed that both types of approach yielded very similar temperature variability predictions over the study 
area. This was not the case for precipitation. Hence, the changes and variability in precipitation data in our study area are more likely to be a product of the models. The 20CR data was preferred over statistically interpolated data as it proved to be more efficient at capturing statistical relationships with TGI data. Mean annual temperature in the simulation experiment was $-3.9^{\circ} \mathrm{C}$ and mean total annual precipitation was $815 \mathrm{~mm}$. The climate warming experienced during the growing season from April to September averaged $0.027^{\circ} \mathrm{Cyr}^{-1}$. No significant change in growing season precipitation was detected (this is consistent with results obtained from Climate Research Unit data).

\subsection{Carbon exchange model}

We used a stand-level process-based model to develop a more complete understanding of relationships observed within the empirical datasets. The bioclimatic model StandLEAP (version 2.1) (Raulier et al., 2000; Girardin et al., 2011b) was used to simulate NPP of jack pine and black spruce forests. StandLEAP is a plot-level model based on the 3PG model (Landsberg and Waring, 1997), and is a generalized stand model applicable to relatively homogeneous forests. StandLEAP is parameterized for individual species, and its application to any particular stand does not require fine-tuning of the model to fit the data. The simulated model data set was used to more fully characterize the impact of many interacting and non-linear modifiers of forest productivity.

In StandLEAP, absorbed photosynthetically active radiation (APAR) is related to GPP using a radiation use efficiency (RUE) coefficient that differs among locations and through time as a function of environmental constraints. Constraints take the form of species-specific multipliers $\left(f_{1} \ldots f_{n}\right)$ that take on a value of 1 under average conditions, closer to zero to represent increasing limitations (e.g. soil water deficit), or above 1.0 as conditions improve towards optimum (e.g. temperature). The following equation summarizes these functions:

$\mathrm{GPP}=\mathrm{APAR} \times\left(\overline{\mathrm{RUE}} \times f_{1} f_{2} \ldots f_{n}\right)$,

where $\overline{\mathrm{RUE}}$ represents a species-specific mean value of RUE. The parameter values have been derived from prior finerscale simulation results of canopy-level GPP and transpiration from a species-specific multi-layer hourly canopy gas exchange model (e.g. Bernier et al., 2001). Representation of photosynthesis in this finer-scale model is based on the equations of Farquhar et al. (1980) parameterized from leaf-level instantaneous gas exchange measurements. NPP is computed monthly after partitioning respiration into growth $\left(R_{\mathrm{g}}\right.$, a fixed proportion of GPP) and maintenance $\left(R_{\mathrm{m}}\right)$ quantities and subtracting these from GPP. $R_{\mathrm{m}}$ is computed as a function of temperature using a $\mathrm{Q}_{10}$ relationship (Agren and Axelsson, 1980; Ryan, 1991; Lavigne and Ryan, 1997).

StandLEAP runs on a monthly time-step and, for this study, results were all aggregated to annual values. The sim- ulations do not include a $\mathrm{CO}_{2}$ fertilization factor because recent studies suggest that this effect is negligible in northern forests (Hickler et al., 2008; Norby et al., 2010; Gedalof and Berg, 2010; Goulden et al., 2010; Girardin et al., 2011b). Also, all carbon flux quantities used in this study were made insensitive to changing forest age over time by assuming that forest attributes (e.g. biomass and stem densities) were fixed across all simulation years; therein the proportion of each class within the studied population remains constant over time. In this experiment, flux quantities solely express direct climate influences on the radiation use efficiency and plant respiration, allowing a direct comparison with the climatically-driven TGI. The strength of this modelling approach is supported by the good performance of StandLEAP in a comparison of its simulation results with measurements by eddy-flux towers (data from Fluxnet-Canada, Margolis et al., 2006) and with TGI data (Girardin et al., 2011a, b).

The detection limit was investigated through a sensitivity analysis in which parameters affecting stand level NPP, such as biomass, stand density and soil water-holding capacity, were varied over a range of plausible conditions. The soil depth was prescribed to range between 200 and $1400 \mathrm{~mm}$ for jack pine, as much of its root system is reported to be in the upper $150 \mathrm{~mm}$, with a taproot that may extend below $2700 \mathrm{~mm}$ on well-drained soils (Rudolph and Laidley, 1990). For black spruce, the depth of the active soil layer was prescribed to range between 200 and $700 \mathrm{~mm}$; while its roots may penetrate to $600 \mathrm{~mm}$, most spread laterally at the mosshumus interface with the bulk of the root biomass being in the upper $200 \mathrm{~mm}$ of the organic horizons (Viereck and Johnston, 1990). Please refer to Girardin et al. (2011b) for more details on the procedure for estimating the value of StandLEAP parameters and data used. Supplement provides further details on the simulation setup.

\subsection{Statistical analyses}

Long-term linear changes in TGI and in simulated carbon fluxes were detected using the four-step procedure described by Yue et al. (2002) in order to correct for biases inherent to serially correlated time series. The procedure consists of: (1) removing trends in data when the slope estimated by the Theil-Sen approach is not equal to zero; (2) prewhitening the detrended data to remove first-order autocorrelation (resulting in a residual series); (3) blending the identified trend and the residual series; and (4) applying the classical MannKendall trend test to the blended series to analyze the statistical significance of the trend. Goodness of fit was described by the coefficient $r$. The period of analysis was set to 19502005 to maximize the robustness of the TGI trend results by provision of sufficient sampled years, and minimize the trend bias inherent to the loss of long-term climate signals in detrended TGI time series (Cook et al., 1995). 
Relationships between slopes of linear trends in TGI, simulated carbon fluxes and explanatory variables (species, stand biomass, stand age, soil texture, rooting extension) were examined using piecewise regression (Friedman, 1991). In the regression analysis, the relationships were described by series of linear segments of differing slopes, each of which was fitted using a basis function. Breaks between segments were defined by a knot in a model that initially over-fitted the data, and was then simplified using a backward/forward stepwise cross-validation procedure. The MARS software was used (Salford Systems, 2001).

Ordination methods are valuable tools in community ecology for identification of complex gradients and generating hypotheses about the relationship between a response variable and the underlying environments. To meet this goal, redundancy analysis (RDA) (Legendre and Legendre, 1998) was used to investigate the relationship between plot-level forest growth and climate. RDA is the canonical extension of PCA and is intended to display the main trends in variation of a multidimensional dataset in a reduced space of a few linearly independent dimensions. In RDA, the canonical axes differ from the principal components (PCs) in that they are constrained to be linear combinations of supplied environmental variables (ter Braak and Prentice, 1988; ter Braak, 1994). RDA may be understood as a two-step process: (i) each TGI time series is regressed on the selected climate variables and the predicted values are computed; and (ii) a PCA is then carried out on the matrix of predicted values to obtain the eigenvalues and eigenvectors (Legendre and Legendre, 1998). The climate variables were selected using a forward selection on the basis of the goodness-of-fit and tested for significance at the $10 \%$ level using 1000 Monte Carlo restricted permutations. Analysis was constrained to the interval 1950-2005. The period of analysis included July of the year previous to ring formation to September of the year of ring formation. For simplicity, our discussion of results was restricted to the first and second canonical axes. RDA was conducted on correlation matrices using the CANOCO 4.0 software (ter Braak and Smilauer, 1998), and scaling of ordination scores was done using correlation biplots. Autocorrelation in the TGI time series was removed prior to RDA using autoregressive modeling (Cook and Kairiukstis, 1992).

\section{Results}

\subsection{Changes in growth from 1950 to 2005}

The analysis of empirical data presented here is based on more than 256000 measurements of tree-ring width collected over a variety of stand ages ranging from 70 to over 300 years since last disturbances and within different environmental settings that impose specific types of constraints on growth. A total of 252 jack pine and black spruce TGI time series, each consisting of on average 2 to 20 ring-width mea- surement series (or 1 to 10 trees, with an average of 4 trees per species per plot; 1228 trees in total), were kept for our analysis. The median length of measurement series is 119 years; $80 \%$ of series have a length exceeding 78 years.

Our analysis of linear trends in the 252 black spruce and jack pine TGI time series highlights a dominating forest growth decline in the PEBNA forest from 1950 to 2005. Nearly two-thirds of the plot-level TGI time series show negative TGI trends and in more than $30 \%$ of cases, the level of the trend was above the critical statistical level (Fig. 2a). Results were robust against the selected time interval for trend analysis (1960-2005 and 1970-2005; Supplement Fig. S2). Differences in direction and level of trends may be accounted for by effects from species dominance, soil types, and stand age (as approximated by the age of the oldest tree in each plot) (Fig. 2). The following model, with the trends of the linear fit to TGI time series as dependent variables and species and environmental settings as independent variables, summarizes these interactions:

$$
\begin{aligned}
\text { TrendTGI } & =0.01543-0.00020 \times \mathrm{BF}_{1}+0.00044 \\
& \times \mathrm{BF}_{2}+0.00949 \times \mathrm{BF}_{3}
\end{aligned}
$$

with

$\mathrm{BF}_{1}=\max (0, \mathrm{AGE}-66)$

$\mathrm{BF}_{2}=\max (0, \operatorname{depthOrg}-2)$

$\mathrm{BF}_{3}=(\operatorname{SAND}(“ 0 ”)) \times \mathrm{BF}_{4}$

$\mathrm{BF}_{4}=(\mathrm{Sb}(“ 1 ”))$.

In Eq. (2), TrendTGI is the rate of change in TGI time series expressed in standardized units per year, SAND denotes the presence of sandy soils (binary variable), AGE is minimum stand age (years), depthOrg is depth of the organic layer $(\mathrm{cm})$, and $\mathrm{Sb}$ denotes the presence of black spruce (binary variable). The model, explaining $43 \%$ of the variance in data ( $n=252$ plots), suggests that TrendTGI progressively decreases below zero as stand age and depth of the organic layer increase (via Eqs. 2a and b), as is also suggested by the biplots of the TrendTGI and environmental variables (Fig. 2e and $\mathrm{f}$ ). The direction and level of TrendTGI is, however, also modulated by soil texture and species presence (respectively Eqs. 2c and d). While declining TGI from 1950 to 2005 is a typical feature of black spruce $\left(\mathrm{BF}_{4}=1\right.$ in its presence; Supplement Fig. S3), this effect is mitigated on sandy soils $\left(\mathrm{BF}_{3}=0\right.$ in the presence of sand; see Fig. 2c).

\subsection{Generating hypotheses on climate factors driving annual growth increments}

The relationship between monthly climate variability and pattern of tree-ring width formation was evaluated using a 

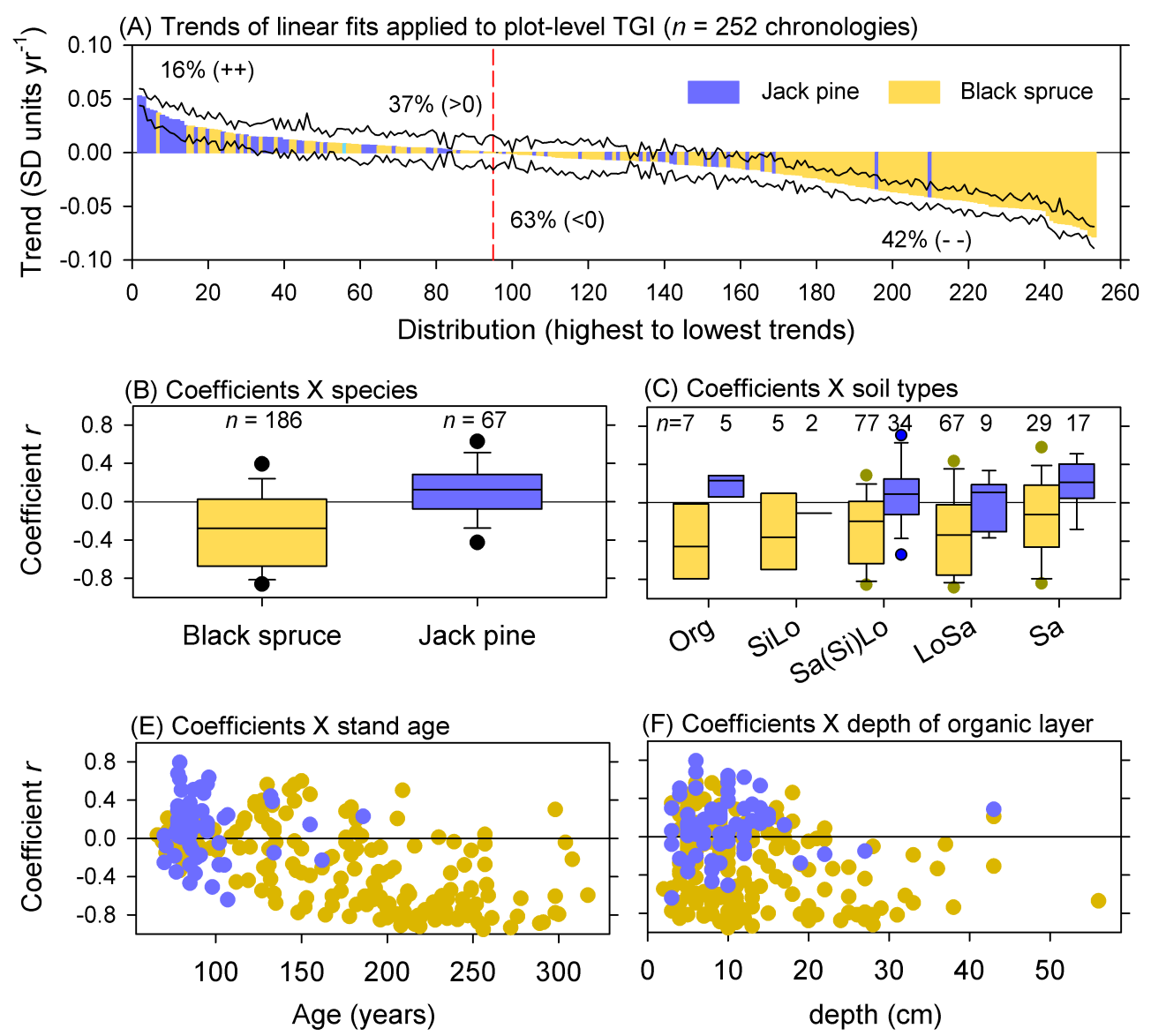

Fig. 2. Results of linear fits for detection of trends applied to 252 plot-level tree growth indices (TGI) of jack pine and black spruce. The period of analysis is 1950-2005. (a) Distribution of slopes of linear fits from highest (left) to lowest (right) and by species. The thin black lines are $90 \%$ confidence intervals; the null hypothesis of "no change" in growth is rejected when "zero" is excluded from the confidence interval. The percentages refer to the number of samples above and below zero, and the number of slopes that passed the statistical significance test. Below are distributions of the coefficients $r$ of linear fits as a function of (b) species, (c) soil types, (d) stand age, and (e) depth of organic layer $(\mathrm{mm})$. Soil texture abbreviations are deep organic (Org), silty-loam (SiLo: fraction of sand 18\%), sandy loam and silty sand (Sa(Si)Lo: fraction of sand $63 \%$ ), loamy-sand (LoSa: fraction of sand $82 \%$ ), and sand (Sa: fraction $91 \%$ ).

multivariate analysis in order to generate hypotheses with respect to causal factors for observed trends in speciesdependent and age-dependent growth. We proceeded with the ordering of the TGI time series in a two-dimensional space using a canonical extension of the principal component analysis carried on the interval 1950-2005. Therein, components were constrained to be linear combinations of supplied monthly climate factors (see Materials and methods). Results show that climate factors with the largest contributions to axis I were current year June daytime temperatures, and previous year July daytime temperatures (Fig. 3). Those contributing to axis II were current year April and May temperatures, and August soil moisture content during the year previous to ring formation. There is no clear interpretation to be made about potential environmental settings (e.g. age, biomass, soil texture, species) and axis I: a positive correlation between loading of this canonical axis and the num- ber of trees used in each plot suggests a partitioning of the data according to the level of signal-to-noise, with the least replicated time series located at the far left of the ordination diagram. In contrast, we may interpret axis II as a stand development gradient with stand age generally increasing from the lowest to the highest values of axis II (Fig. 3). The overlap of jack pine data with mature black spruce data in the lowest range of axis II is indicative of covarying year-to-year behaviour in both species at a similar stand age, an interpretation supported by observations of TGI time series (Fig. 4). This covariance falls apart as data from the lowest range of axis II are compared with black spruce data from the highest range of axis II (Fig. 4).

In light of these results, we postulate that spring daytime temperatures and late summer soil moisture of the previous year significantly modulate forest growth in PEBNA forests, with stand age mediating the strength of this modulation. 


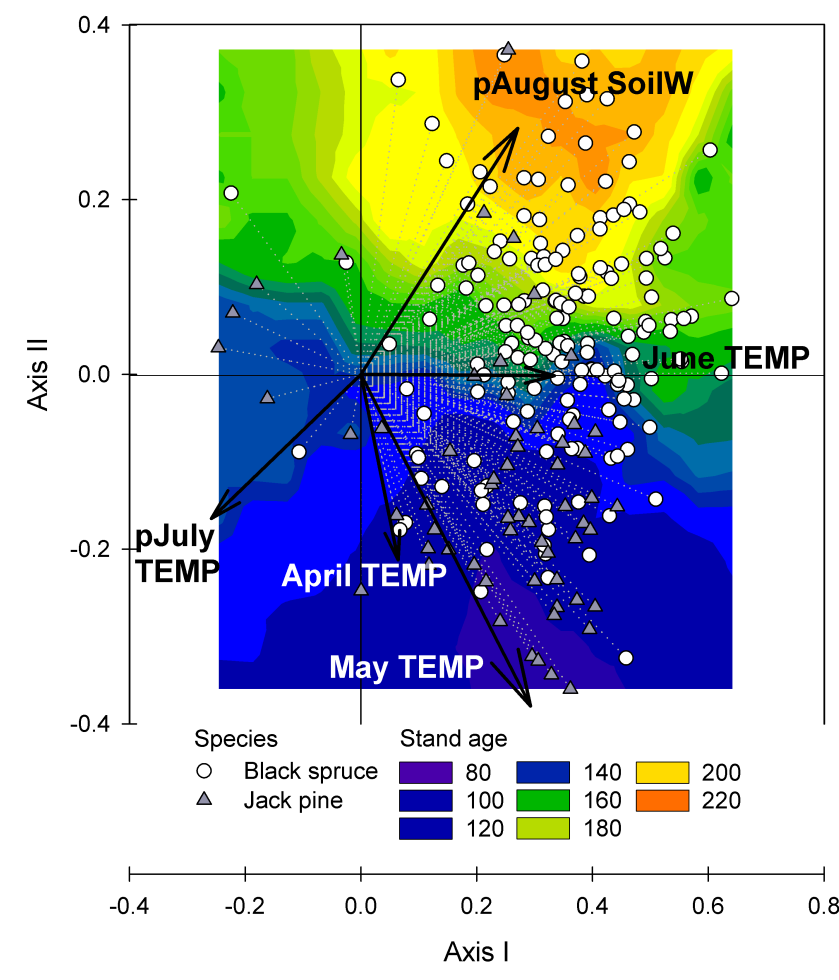

Fig. 3. Eigenvectors of the redundancy analysis (RDA) conducted on the rectangular matrix of 252 plot-level TGI time series using the interval 1950-2005. Climate variable abbreviations are "TEMP" for daytime temperature and "SoilW" for soil water content. The " $p$ " preceding a given month indicates a variable affecting growth the following calendar year. The descriptors (arrows) are positioned in the biplot based on their correlations with the canonical axes (for climate variables, multiply by two). For instance, the variable MayTEMP has a correlation of 0.59 with the first canonical axis and of -0.76 with the second one. In addition, the biplot also approximates the correlation coefficient among TGI time series and climate variables (Legendre and Legendre 1998). Variables with "arrows" at sharp angles are positively correlated $\left(\cos 0^{\circ}=1.0\right.$, i.e. perfect correlation). Conversely, obtuse angles indicate negative correlation $\left(\cos 180^{\circ}=1.0\right.$, i.e. perfect correlation). Eigenvalues (E) and descriptors - climate correlation coefficients are $E_{1}=0.12$, $E_{2}=0.02, r_{1}=0.70$, and $r_{2}=0.72$; percentage of explained variance of descriptors - climate relations are canonical axis $I=0.64$ and canonical axis II $=0.11$. A contour plot of the stand age variable across the two-dimensional RDA space is also shown; the correlation between the stand age variable and loading of canonical axis II is $0.52(P<0.001)$.

Overmature stands tend to be the least affected by current year spring daytime temperature variability (Supplement Fig. S4), but the most affected by the summer soil water content and temperature of the previous year. Hence, the direction and level of changes seen in TrendTGI (Fig. 2) could reflect the combined effects of environmental settings, species dominance, and physiological responses to changing temperatures and soil moisture content.
(A) Black spruce

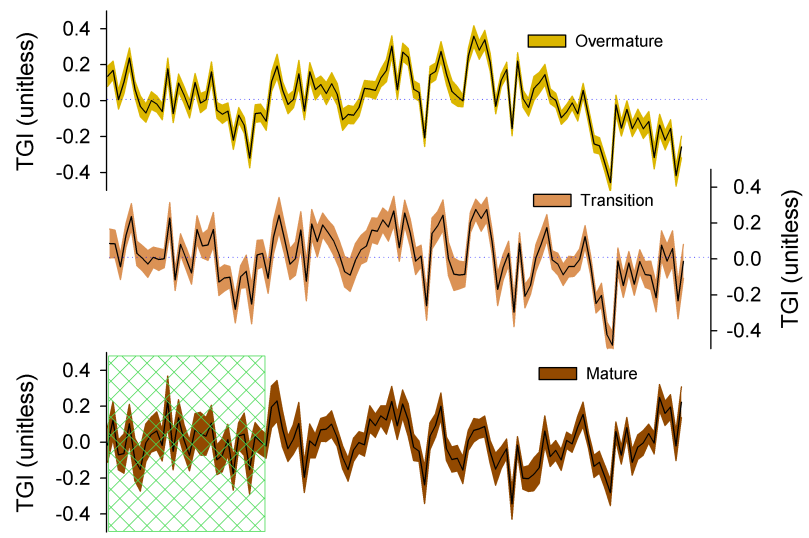

(B) Jack pine

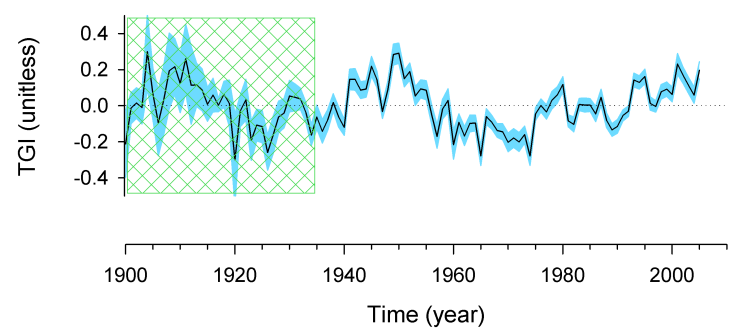

Fig. 4. Means of (a) black spruce and (b) jack pine plot-level TGI time series computed over 1900 to 2005 with $90 \%$ confidence intervals. Black spruce plot-level TGI time series were pooled according to their position along axis II of the RDA ordination diagram (Fig. 3), with "mature" gathering all plot-level TGI time series with axis II loading from -0.40 to -0.05 , "transition" gathering those with loading from -0.05 to 0.05 , and "overmature" gathering those between 0.05 and 0.40 .

\subsection{A mechanistic process-based modeling approach}

Unlike the analyses of empirical data which were restricted to mature and overmature stands (with biomass ranging from 25 to $160 \mathrm{M} \mathrm{g} \mathrm{ha}^{-1}$ ), the modeling experiment presented here includes the full spectrum of stand developmental stages (biomass from $\sim 1$ to $200 \mathrm{Mg} \mathrm{ha}^{-1}$ ). Model results successfully recreated the heterogeneous pattern of trends in forest growth inferred from the analysis of the TGI time series (Fig. 5a). In agreement with empirical data, we found high increases of NPP in jack pine dominated forests from 1950 to $2005\left(+0.17 \mathrm{gC} \mathrm{m}^{-2} \mathrm{yr}^{-1}\right.$ with $90 \%$ confidence interval $(\mathrm{CI})[0.14,0.20]$, i.e. $+5.1 \%$ in total relative to longterm mean NPP) (Fig. 5b). In comparison, black spruce forests show moderate changes in the level of productivity $\left(+0.06 \mathrm{gC} \mathrm{m}^{-2} \mathrm{yr}^{-1}\right.$ with $90 \%$ CI $[0.03$, 0.09], i.e. $+2.1 \%)$. Our model results suggest that species' dominance and stand attributes (i.e. biomass, Fig. 5d) are determining factors for the direction and level of responses to ongoing climatic changes. The soil water-holding capacity is also a significant mediating factor (Fig. 5b). The following model, accounting 
for $73 \%$ of the variance in data $(n=284$ plots), summarizes the various interactions:

$$
\begin{aligned}
\text { TrendNPP } & =-0.00187-0.00005 \times \mathrm{BF}_{5} \\
& +0.00021 \times \mathrm{BF}_{6}+0.00611 \times \mathrm{BF}_{7} \\
& -0.00798 \times \mathrm{BF}_{8}+0.00402 \times \mathrm{BF}_{9}
\end{aligned}
$$

with

$\mathrm{BF}_{5}=\max (0,550-$ depth $)$

$\mathrm{BF}_{6}=\max (0,107-$ biomass $)$

$\mathrm{BF}_{7}=(\mathrm{Sb}(“ 0 ”))$

$\mathrm{BF}_{8}=(\operatorname{SAND}(“ 1 ”))$

$\mathrm{BF}_{9}=(\operatorname{LoSAND}(“ 0 ”)$

where TrendNPP is the rate of change in NPP (expressed in standardized units), depth defines the soil depth parameter $(\mathrm{mm})$ for the soil water-holding capacity, biomass is stand biomass $\left(\mathrm{Mg} \mathrm{ha}^{-1}\right)$, Sb denotes the presence of black spruce, and SAND and LoSAND denote the presence of sand and loamy sand. Therein, the model suggests that the slope of the trend progressively increases as soil water-holding capacity increases up to a depth of the active soil layer of about $550 \mathrm{~mm}$ (Eq. 3a), as is also suggested by the biplot shown in Fig. 5c. On the other hand, increasing stand biomass contributes significantly to a lowering of the trend (via Eq. 3b) from about $107 \mathrm{Mg} \mathrm{ha}^{-1}$ and over (see Fig. 5e). A declining trend is exacerbated by the presence of black spruce in the stand $\left(\mathrm{BF}_{7}\right.$ takes values of zero in its presence), sand $\left(\mathrm{BF}_{8}\right.$ takes values of one in its presence), and loamy sand $\left(\mathrm{BF}_{9}\right.$ takes values of zero in its presence). Hence, old-growth black spruce forests are "typically" associated with decreasing net forest production according to the modeling results, which is consistent with analyses of the TGI time series.

Species responses to climate ultimately depend on their efficiency to use resources for production of biomass. Analyses of the climate modifiers affecting radiation use efficiency first indicate that the two species have seen a lowering of their temperature constraints (hereafter $f_{\text {Temp }}$ ) toward the later part of the studied period (Fig. 6c). This effect was largely due to a longer growing season (rate of warming of $0.027^{\circ} \mathrm{C} \mathrm{yr}^{-1}$; see Materials and methods). Black spruce has benefited more from the warming with rates of changes in $f_{\text {Temp }}$ slightly higher throughout almost all the growing season (Fig. 6c). However, black spruce, in comparison with jack pine, has lower water use efficiency (ratio of monthly carbon assimilation rate to transpiration rate: $0.32 \mathrm{~mol} \mathrm{C} \mathrm{mm}^{-1} \mathrm{H}_{2} \mathrm{O}$ for black spruce versus $0.40 \mathrm{~mol} \mathrm{C} \mathrm{mm}^{-1} \mathrm{H}_{2} \mathrm{O}$ for jack pine) and modeled soil water-holding capacity (Fig. 5c and Materials and methods). Hence, black spruce assimilation rates seemed further limited by increasingly constrained soil water availability $\left(f_{\mathrm{SWD}}\right)$, particularly in spring (Fig. 6d). For this species, the water availability constraint was sufficient to offset some of the benefits of a warming climate.

Our model results suggest that changes in autotrophic respiration have a decisive effect on the NPP trend. TrendNPP tends to reach the lower bound of its frequency distribution (Eq. 3) in old-growth stands, where GPP is low but respiration is high owing to a large pool of standing biomass. This effect is exacerbated under increasing temperatures when an increase in GPP is insufficient to compensate for increased respiration demands. Observation of carbon use efficiency (CUE) values, i.e. the ratio of net primary productivity to gross primary productivity, suggests a transition to a negative TrendNPP in PEBNA forests at a critical CUE of approximately 0.40 (Fig. $5 \mathrm{~g}$ and Fig. 7). In stands of low to moderate standing biomass $\left(<50 \mathrm{Mg} \mathrm{ha}^{-1}\right)$, rates of increase in GPP are more than sufficient to compensate for the increasing respiration (Fig. 6). In contrast, simulation results suggest that the likelihood of recording a negative trend in NPP increases as low-CUE stands exceed an aboveground biomass of $50 \mathrm{Mg} \mathrm{ha}^{-1}$ (Fig. 7). A high and positive correlation between TrendTGI and a measure of stand productivity defined by the biomass-to-AGE ratio provides support for these inferences (Spearman $r=0.49, P<0.001 ; N=252$ ): stands in which annual biomass increment is low tend to show negative TrendTGI, and vice versa.

\section{Discussion}

In their analysis of productivity changes estimated from a carbon cycle model driven by high spatial resolution satellite records, Hicke et al. (2002) reported for the study area a negative trend in annual NPP of approximately $2.0 \mathrm{gC} \mathrm{m}^{-2} \mathrm{yr}^{-2}$ for the period from 1982 to 1998 . This represents a decline in forest production of roughly $10 \%$ for the 17 years under study. Declines in forest production in this boreal region have also been documented by Wang et al. (2011) (period 1982-2006) and de Jong et al. (2012) (period 1982-2008). By contrast, Nemani et al. (2003) found no such tendency from a similar analysis covering the 19821999 period. Our analyses of the 252 plot-level TGI time series are consistent with estimates of Hicke et al. (2002), Wang et al. (2011) and de Jong et al. (2012) and highlight a trend of declining forest growth in PEBNA forests from 1950 to 2005. However, our results also suggest that these changes are not evenly distributed across all forest stands. Black spruce dominated and overmature stands ( $>120$ years) 

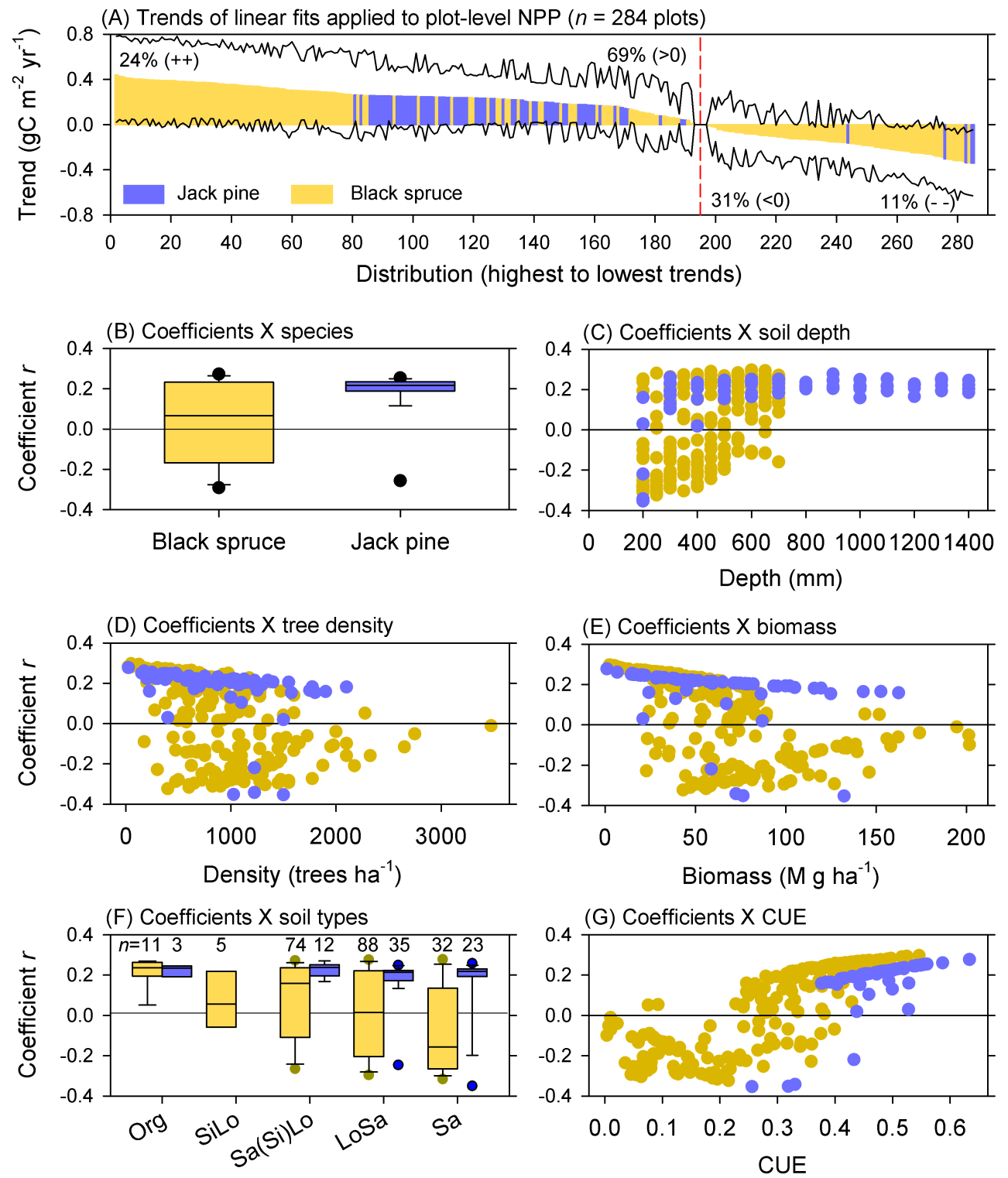

Fig. 5. Results of linear fits for detection of trends applied to 284 plot-level simulations of net primary production (NPP) of jack pine and black spruce stands. The period of analysis is 1950-2005. (a) Distribution of regression slopes with $90 \%$ confidence intervals. Distributions of the coefficients $r$ of linear fits as a function of (b) species, (c) depth of the active soil layer, (d) stand density, (e) stand biomass, (f) soil types, and (g) carbon use efficiency (CUE, i.e. the ratio of net primary productivity to gross primary productivity). Refer to Fig. 2 for definitions.

experienced significant growth declines during the studied period (39\% of all our studied plots), but jack pine dominated stands and mature black spruce stands ( $70-120$ years) had increasing growth (12\% of all our studied plots) or an absence of change in growth ( $49 \%$ of all our studied plots). This observation of uneven trends in growth over time in PEBNA forests may partially explain the outcome of the $\mathrm{Ne}$ mani et al. (2003) study. Length of the time period covered could also explain the difference. To our knowledge, there is no longer-term assessment of forest productivity changes in this boreal region other than the one presented by this study.

Differences in direction and level of trends in plot-level TGI time series were explained by demographic and species traits, soil types and active layer depths. The importance of demographic traits like age and size in relation to rates of carbon assimilation in forests is well recognized. In boreal forests, a drop in carbon assimilation associated with ageing has notably been attributed to decreasing nutrient availability and increasing rates of plant respiration and mortality 

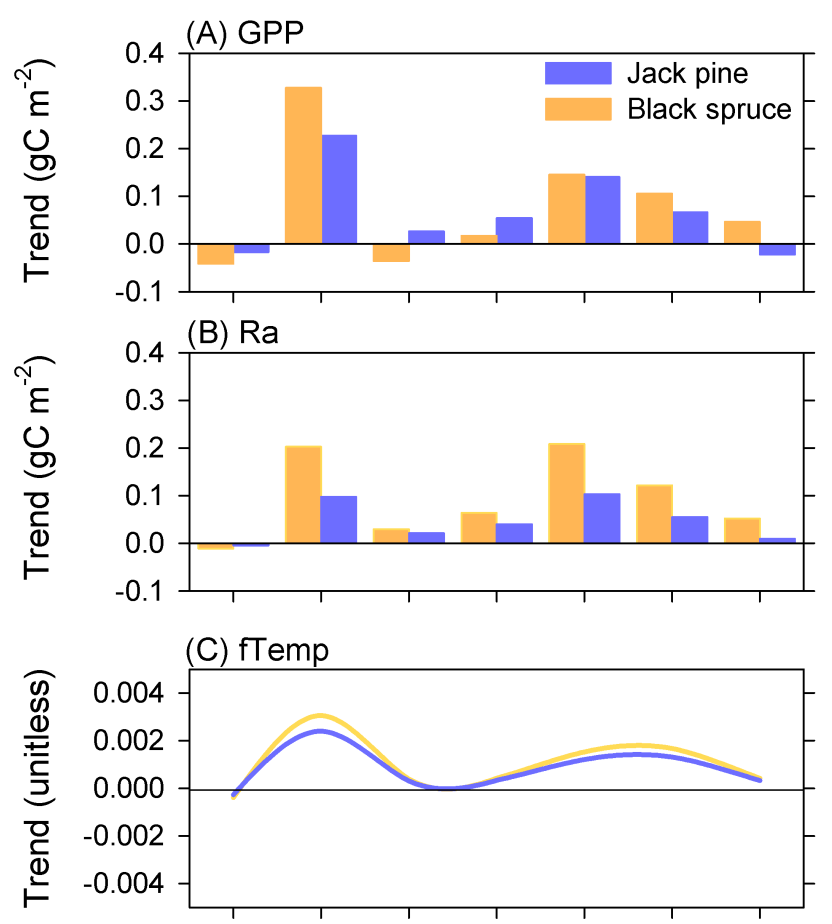

(D) fSWD

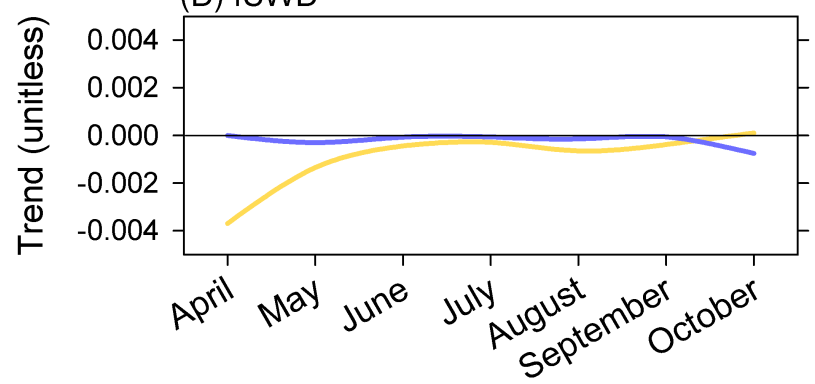

Fig. 6. Results of linear fits for detection of trends in speciesaveraged plot-level monthly simulations ( $n=284$ plots) of (a) gross primary productivity (GPP), (b) autotrophic respiration (Ra), (c) temperature modifiers of radiation use efficiency $\left(f_{\text {Temp }}\right)$, and (d) soil water deficit modifiers of radiation use efficiency $\left(f_{\mathrm{SWD}}\right)$. Positive trends in $f_{\text {Temp }}$ and $f_{\text {SWD }}$ indicate that growth conditions are improving towards optimum; negative trends indicate increasing limitations.

(e.g. Mencuccini et al., 2005; Kashian et al., 2006; Zaehle et al., 2006; Luyssaert et al., 2008; Goulden et al., 2010). In the absence of disturbances, an ageing forest landscape will therefore have decreasing carbon assimilation. Less recognized is the role of demographic traits in changing forest sensitivity to particular constraints like climate. It is only recently that information on age/size-dependency of climate processes governing forest growth has been acquired. Such information is mostly being derived from the analysis of wood formation, notably from analysis of annual TGI (e.g. Szeicz and MacDonald, 1994; Carrer and Urbinati, 2004; Vieira et al., 2009; Copenheaver et al., 2011) and of

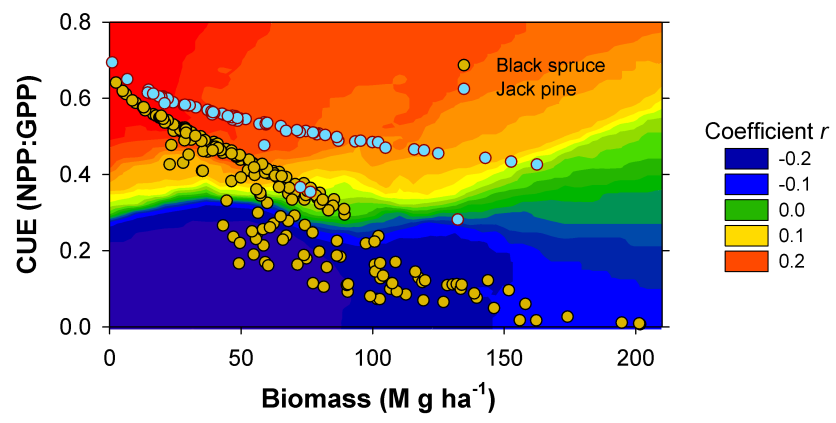

Fig. 7. Relationship between simulated carbon use efficiency (CUE) and aboveground stand biomass. A contour plot of the trends in NPP (as indicated by the strength coefficient $r$ ) over 1950-2005 across the two-dimensional space is also shown.

cambial activity in living trees (e.g. Rossi et al., 2008). Our analyses of TGI time series and model simulation outputs suggest that not only are demographic traits controlling forest responses to climate variability, but they also mediate the direction of forest changes in a setting of changing climate conditions. Forest stands entering the mature successional stage are positive responders to climate warming in PEBNA forests, and this response reverses as stands enter into the overmature stage. The relationship between successional stages, age and biomass would thus be accelerated in these forests under a changing climate. These kinds of demography-dependent responses have led many authors to underline the need to consider tree age when predicting their response to future climate changes (e.g. Carrer and Urbinati, 2004; Vieira et al., 2009; Copenheaver et al., 2011) and $\mathrm{CO}_{2}$ fertilization effects (e.g. Körner et al., 2005).

The exact physiological mechanisms driving the decline in tree growth with age is not a fully resolved issue (e.g. Ryan et $\mathrm{al}, 2006$ ). From our modeling perspective, the increasing importance of autotrophic respiration relative to GPP in stands with larger standing biomass accounts for much of the variation in the direction and level of trends in NPP. This interpretation is in line with evidence from recent meta-analysis of global C-fluxes (Piao et al., 2010). This influence is exacerbated in soils with low water-holding capacity. The lower water-use efficiency of black spruce in comparison with jack pine dominated stands (Sullivan et al., 1997) further contributes to the disparity between the two species. Indeed, our results suggest that for older black spruce-dominated stands, the benefits to growth resulting from a longer growing season over the period under study is disproportionally low in comparison with the moisture stress and respiration losses brought about by warmer summer temperatures (Fig. 6). This inferred causality may help explain the ordering of the plot-level TGI in the climatically-constrained ordination (Fig. 3), in which overmature black spruce forests were found in an area of the ordination diagram in which annual growth increment was the least correlated with spring 
temperatures (positive correlation) and more strongly correlated with summer moisture availability (positive correlation) and July temperatures (negative correlation). This response pattern of overmature black spruce in comparison with pine species is consistent with observations reported from other boreal regions (Girardin et al., 2006, their Fig. 2) and the simulated data (Supplement Fig. S5).

The balance between young and old-stands in the landscape is dictated by the annual rate of disturbance (Johnson and Gutsell, 1994) and our modeling experiment assumes that this rate was constant across all simulation years. In other words, we made the assumption that the landscape had the same proportion of age classes across all simulation years. This assumption facilitated the interpretation of factors of causality for growth declines by ensuring that other factors modulating carbon exchanges at the landscape level were kept constant. The reality, however, is that the amount of burned area in northern Quebec's forests more than doubled between 1940-1979 and 1980-2006 (Mansuy et al., 2010). The age-class distribution of PEBNA forest stands is likely to be skewed toward younger stands in recent years, a change that is important if results are to be extrapolated at the landscape level. Notably, the proportion of stands of age $>120$ years in landscapes that undergo changes in burn rates from $0.5 \% \mathrm{yr}^{-1}$ to $1.0 \% \mathrm{yr}^{-1}$ can decrease roughly from $50 \%$ to $30 \%$ (Johnson and Gutsell, 1994), assuming that the probability of burning is equal across all forest stand ages (e.g. no fuel limitation, Krawchuk and Cumming, 2011). At the landscape level, the trend of decreasing growth in old-growth stands may be counterbalanced by the increasing proportion of stands in younger age classes, if these younger stands have also seen a lowering of their growth constraints in recent years and if their regeneration is as successful as during preceding periods. However, changes in growth conditions for these stands are currently uncertain since our empirical analysis did not include information from young and immature stands.

The data-model comparison undertaken here suggests that simple carbon exchange models can adequately simulate age/size and species-dependent responses to climate. This being said, the experiment relies on key assumptions and excludes many intrinsic (e.g. effects from hydraulic conductivity and genetic control on development processes) and extrinsic processes (e.g. effects from nutrient cycling, soil thaw, insect infestation) regulating forest growth. An important source of uncertainty in the simulation experiment is the general lack of information on soil water-holding capacity, a variable that is needed to generate good estimates of forest productivity at a given stand age (Ryan et al., 2006). As shown by the sensitivity analysis carried out via Eq. 3, minor variations in soil water-holding capacity through modification of soil depths yield a range of scenario outcomes (see Girardin et al., 2008). Additionally, our simulations are inherently dependent on the quality of data used to drive the carbon model. Because the climate data used as input to
StandLEAP are likely to be a product of the 20CR climate model (see Materials and methods), they inevitably induce some uncertainty in the climate trends which might also be carried over into the modeled estimates of the NPP trend. Simulation experiments conducted using Climate Research Unit TS2.1 gridded data as climate input yielded results that were very similar to those reported in this study with respect to the distribution of regression slopes. Nevertheless, uncertainties in climate data have an effect on the empirical models of forest growth and climate relationships: interpretation of the climate drivers of forest growth (i.e. Fig. 3) should be done cautiously in light of the suboptimal moisture data.

Other uncertainties arise from the data processing of the tree-ring width measurement series and determination of stand age. The detrending procedure applied to individual ring-width measurement series can inevitably remove some of the long-term climate-driven variability, and this effect is proportional to the length of individual ring-width measurement series being treated (Cook et al., 1995). This limitation can increase the proportion of false negative results when analyzing trends in short TGI time series, and perhaps lead to an apparent demographic-related trend in forest growth as observed in the current study. That said, application of a conservative detrending procedure in which ring-width measurements were scaled against an expectation of growth for the appropriate age of each ring (i.e. the Regional Curve Standardization technique; Esper et al., 2003) supports the robustness of the results for mature forests for the period under study (Girardin, 2012; Supplement Fig. S6). Additionally, we found that demographic and species differences in direction and levels of trends persist after the application of a flexible detrending technique to the ring-width measurements (i.e. 80-year smoothing splines; Supplement Fig. S9). The higher frequency variability (interannual to multidecadal) that characterizes the period under study remains largely unaffected by the application of detrending. However, other errors may originate from the approach of determining stand age. Jack pine is a shade-intolerant species that is replaced by black spruce when the trees from the first cohort die after about 100 years since fire. Once into this secondary black spruce dominance phase, time-since-fire becomes increasingly difficult to determine because of the disappearance of the post-fire regenerated trees (Pollock and Payette, 2010). Small fires through the stands and their triggering of multiple-age cohorts may also induce some errors in estimates of stand attributes. These errors could affect the age model developed through Eq. 2, such that the onset and extent of the declining trend seen in Fig. 2e after 120 years of age may be imprecise. 


\section{Conclusions}

Our study is the first to report on growth trends in PEBNA forests from the analysis of a highly replicated plot-level tree growth increment dataset. While our analysis highlights a dominant forest growth decline in PEBNA forest from 1950 to 2005, it also highlights the presence of heterogeneity in growth trends. Variability in trends is consistent with the process-based modeling experiment, whose results suggest age and size-dependent temperature and moisture constraints on carbon use efficiency. This age-dependency of tree growth response to climate underscores the need to consider landscape-level responses when simulating future forest growth and carbon dynamics. At the landscape level, stand age distribution is the result of age-class legacy as well as of the disturbances that act on stand mortality at landscape levels. The strong coupling between these disturbances, in particular fire, and climate thus provide a dynamic feedback mechanism. Predicted increases in fire frequency (e.g. Balshi et al., 2009) will result in younger forests and the maintenance of jack pine forests, thereby enhancing the positive response of landscape-level forest growth to climate change in PEBNA forests.

\section{Contributions}

M. P. G. conceived and designed the study, supervised the development of the tree-ring data, conducted the simulation work, and wrote the manuscript. F. R., P. Y. B. and X. J. G. conducted the parameterization of the simulation model. M. P. G. and X. J. G. performed statistical analyses of tree-ring and simulation data. All authors discussed the results and commented on the manuscript. P. Y. B. edited the manuscript. S. G. provided liaison with the Programme d'inventaire écoforestier nordique, ministère des Ressources naturelles et de la Faune du Québec.

\section{Competing financial interests}

The authors declare no competing financial interests.

\section{Supplementary material related to this article is available online at: http://www.biogeosciences.net/9/ 2523/2012/bg-9-2523-2012-supplement.pdf.}

Acknowledgements. The study was made possible thanks to the financial and in-kind support provided by the ministère des Ressources naturelles et de la Faune du Québec (MRNFQ) and the Fonds de recherche du Québec - Nature et technologies (FQRNT) Programme aménagement et environnement forestier III. We acknowledge the important contribution of the MRNFQ, from whom most of the data were obtained; without this contribution, this study could not have been conducted. Additional funds for this research were provided by the Canadian Forest Service operating budgets. We thank Marie-Noëlle Carron, Christine Simard, Étienne Du Berger and Giancarlo Marino for assistance with the laboratory work. We thank two referees for their helpful comments. The 20th Century Reanalysis data were provided by the NOAA/OAR/ESRL PSD, Boulder, Colorado, USA (http://www.esrl.noaa.gov/psd/).

Edited by: K. Thonicke

\section{References}

Agren, G. I. and Axelsson, B.: Population respiration: a theoretical approach, Ecol. Model., 11, 39-54, 1980.

Balshi, M. S., McGuire, A. D., Duffy, P., Flannigan, M., Walsh, J., and Melillo, J.: Assessing the response of area burned to changing climate in western boreal North America using a Multivariate Adaptive Regression Splines (MARS) approach, Glob. Change Biol., 15, 578-600, 2009.

Beck, P. S. A., Juday, G. P., Alix, C., Barber, V., Winslow, S., Sousa, E., Heiser, P., Herriges, J., and Goetz, S. J.: Changes in forest productivity across Alaska consistent with biome shift, Ecol. Lett., 14, 373-379, 2011.

Bernier, P. Y., Raulier, F., Stenberg, P., and Ung, C.-H.: Importance of needle age and shoot structure on canopy net photosynthesis of balsam fir (Abies balsamea): a spatially inexplicit modeling analysis, Tree Physiol., 21, 815-830, 2001.

Carrer, M. and Urbinati, C.: Age-dependent tree ring growth responses to climate of Larix decidua and Pinus cembra in the Italian Alps, Ecology, 85, 730-740, 2004.

Chen, J. M., Ju, W., Cihlar, J., Price, D., Liu, J., Chen, W., Pan, J., Black, A., and Barr, A.: Spatial distribution of carbon sources and sinks in Canada's forests, Tellus B, 55, 622-641, 2003.

Compo, G. P., Whitaker, J. S., Sardeshmukh, P. D., Matsui, N., Allan, R. J., Yin, X., Gleason, B. E., Vose, R. S., Rutledge, G., Bessemoulin, P., Brönnimann, S., Brunet, M., Crouthamel, R. I., Grant, A. N., Groisman, P. Y., Jones, P. D., Kruk, M., Kruger, A. C., Marshall, G. J., Maugeri, M., Mok, H. Y., Nordli, Ø., Ross, T. F., Trigo, R. M., Wang, X. L., Woodruff, S. D., and Worley, S. J.: The Twentieth Century Reanalysis project. Q. J. R. Meteorol. Soc., 137, 1-28, 2011.

Cook, E. R. and Kairiukstis, L. A.: Methods of Dendrochronology: Applications in the Environmental Sciences, Kluwer Academic Publishers, 392 pages, 1992.

Cook, E. R., Briffa, K. R., Meko, D. M., Graybill, D. A., and Funkhouser, G.: The "segment length curse" in long tree-ring chronology development for palaeoclimatic studies, Holocene 5, 229-237, 1995.

Cook, E. R. and Peters, K.: Calculating unbiased tree-ring indices for the study of climatic and environmental change, Holocene, 7 , 361-370, 1997. 
Copenheaver, C. A., Crawford, C. J., and Fearer, T. M.: Age-specific responses to climate identified in the growth of Quercus alba, Trees, 25, 647-653, 2011.

De Jong, R., Verbesselt, J., Schaepman, M. E., and de Bruin, S.: Trend changes in global greening and browning: contribution of short-term trends to longer-term change, Glob. Change Biol., 18, 642-655, 2012.

Esper, J., Cook, E. R., Krusic, P. J., Peters, K., and Schweingruber, F. H.: Tests of the RCS method for preserving low-frequency variability in long tree-ring chronologies, Tree-Ring Res., 59, 81-98, 2003.

Fan, Y. and Huug van den Dool, J.: Climate Prediction Center global monthly soil moisture data set at 0.5 degree resolution for 1948 to present, J. Geophys. Res., 109, D10102, doi:10.1029/2003JD004345, 2004.

Farquhar, G. D., von Caemmerer, S., and Berry, J. A.: A biochemical model of photosynthetic $\mathrm{CO}_{2}$ assimilation in leaves of $\mathrm{C}_{3}$ species, Planta, 149, 78-90, 1980.

Friedman, J. H.: Multivariate adaptive regression splines, Ann. Stat., 19, 1-67, 1991.

Gedalof, Z. and Berg, A. A.: Tree ring evidence for limited direct $\mathrm{CO}_{2}$ fertilization of forests over the 20th century, Global Biogeochem. Cycles, 24, GB3027, doi:10.1029/2009GB003699, 2010.

Girardin, M. P.: Interactive comment on "Changes in growth of pristine boreal North American forests from 1950 to 2005 driven by landscape demographics and species traits", Biogeosciences Discuss., 9, C292-C300, 2012.

Girardin, M. P., Raulier, F., Bernier, P. Y., and Tardif J. C.: Response of tree growth to a changing climate in boreal central Canada: a comparison of empirical, process-based, and hybrid modelling approaches, Ecol. Model., 213, 209-228, 2008.

Girardin, M. P., Bernier, P. Y., and Gauthier, S.: Increasing potential NEP of eastern boreal North American forests constrained by decreasing wildfire activity, Ecosphere, 2, art25, 2011 a.

Girardin, M. P., Bernier, P. Y., Raulier, F., Tardif, J. C., Conciatori, F., and Guo, X. J.: Testing for a $\mathrm{CO}_{2}$ fertilization effect on growth of Canadian boreal forests, J. Geophys. Res., 116, G01012, doi:10.1029/2010JG001287, 2011b.

Girardin, M.-P., Tardif, J. C., Flannigan, M. D., and Bergeron, Y.: Synoptic-scale atmospheric circulation and boreal Canada summer drought variability of the past three centuries, J. Climate, 19, 1922-1947, 2006.

Goulden, M. L., McMillan, A. M. S., Winston, G. C., Rocha, A. V., Manies, K. L., Harden, J. W., and Bond-Lamberty, B. P.: Patterns of NPP, GPP, respiration, and NEP during boreal forest succession. Glob. Change Biol., 17, 855-871, 2010.

Hicke, J. A., Asner, G. P., Randerson, J. T., Tucker, C., Los, S., Birdsey, R., Jenkins, J. C., Field, C., and Holland, E.: Satellitederived increases in net primary productivity across North America, 1982-1998, Geophys. Res. Lett., 29, 1427, 2002.

Hickler T., Smith, B., Prentice, I. C., Mjofors, K., Miller, P., Arneth, A., and Sykes, M. T.: $\mathrm{CO}_{2}$ fertilization in temperate FACE experiments not representative of boreal and tropical forests, Glob. Change Biol., 14, 1531-1542, 2008.

Holmes, R. L.: Computer-assisted quality control in tree-ring dating and measurement. Tree-Ring Bulletin 43, 69-78, 1983.

Johnson, E. A. and Gutsell, S. L.: Fire frequency models, methods and interpretations, Adv. Ecol. Res., 25, 239-287, 1994.
Kashian, D. M., Romme, W. H., Tinker, D. B., Turner, M. G., and Ryan, M. G.: Carbon storage on landscapes with stand-replacing fires, BioScience, 56, 598-606, 2006.

Körner, C., Asshoff, R., Bignucolo, O., Hättenschwiler, H., Keel, S. G., Peláez-Riedl, S., Pepin, S., Siegwolf, R. T. W., and Zotz, G.: Carbon flux and growth in mature deciduous forest trees exposed to elevated $\mathrm{CO}_{2}$, Science, 309, 1360-1362, 2005.

Krawchuk, M. A. and Cumming, S.: Effects of biotic feedback and harvest management on boreal forest fire activity under climate change, Ecol. Appl., 21, 122-136, 2011.

Lambert, M.-C., Ung, C.-H., and Raulier, F.: Canadian national tree aboveground biomass equations, Can. J. For. Res., 35, 19962018, 2005.

Landsberg, J. J. and Waring, R. H.: A generalised model of forest productivity using simplified concepts of radiation-use efficiency, carbon balance and partitioning, For. Ecol. Manag., 95, 209-228, 1997.

Lavigne, M. B. and Ryan, M. G.: Growth and maintenance respiration rates of aspen, black spruce and jack pine stems at northern and southern BOREAS sites, Tree Physiol., 17, 543-551, 1997.

Legendre, P. and Legendre L.: Numerical ecology. New York, Elsevier, $853 \mathrm{pp}, 1998$.

Létourneau, J. P., Matejek, S., Morneau, C., Robitaille, A., Roméo, T., Brunelle, J., and Leboeuf, A.: Norme de cartographie écoforestière du Programme d'inventaire écoforestier nordique. Ministère des Ressources naturelles et de la Faune du Québec: Québec, QC, 2008.

Luyssaert, S., Schulze, E.-D., Börner, A. Knohl, A., Hessenmöller, D., Law, B. E., Ciais, P., and Grace, J.: Old-growth forests as global carbon sinks, Nature, 455, 213-215, 2008.

Mansuy, N., Gauthier, S., Robitaille, A., and Bergeron, Y.: The effects of surficial deposit-drainage combinations on spatial variations of fire cycles in the boreal forest of eastern Canada, Int. J. Wildland Fire, 19, 1083-1098, 2010.

Margolis, H. A., Flanagan, L. B., and Amiro, B. D.: The FluxnetCanada Research Network: Influence of climate and disturbance on carbon cycling in forests and peatlands, Agric. For. Meteorol., 140, 1-5, 2006.

Medlyn, B. E., Duursma, R. A., and Zeppel, M. J. B.: Forest productivity under climate change: a checklist for evaluating model studies, Wiley Interdiscip. Rev. Clim. Change 2, 332-335, 2011.

Mencuccini, M., Martínez-Vilalta, J., Vanderklein, D., Hamid, H.A., Korakaki, E., Lee, S., and Michiels, B.: Size-mediated ageing reduces vigour in tall trees, Ecol. Lett., 8, 1183-1190, 2005.

Metsaranta, J. M., Kurz, W. A., Neilson, E. T., and Stinson, G.: Implications of future disturbance regimes on the carbon balance of Canada's managed forest (2010-2100), Tellus B, 62, 719-728, 2010.

Michaelian, M., Hogg, E.H., Hall, R.J., and Arsenault, E.: Massive mortality of aspen following severe drought along the southern edge of the Canadian boreal forest, Glob. Change Biol., 17, 2084-2094, 2011.

Ministère des Ressources naturelles du Québec (MRNFQ): la limite nordique des forêts attribuables. Rapport final du comité. Ministère des Ressources naturelles, Gouvernement du Québec, Québec, Québec, 2000.

Mitchell, T. D. and Jones, P. D.: An improved method of constructing a database of monthly climate observations and associated high-resolution grids, Int. J. Climatol., 25, 693-712, 2005. 
Nemani, R. R., Keeling, C. D., Hashimoto, H., Jolly, W. M., Piper, S. C., Tucker, C. J., Myneni, R. B., and Running, S. W.: Climatedriven increases in global terrestrial net primary production from 1982 to 1999, Science, 300, 1560-1563, 2003.

Norby R. J., Warren, J. M., Iversen, C. M., Medlyn, B. E., and McMurtriec, R. E.: $\mathrm{CO}_{2}$ enhancement of forest productivity constrained by limited nitrogen availability, Proc. Natl. Acad. Sci. USA, 107, 19368-19373, 2010.

Piao, S., Luyssaert, S., Ciais, P., Janssens, I. A., Chen, A., Cao, C., Fang, J., Friedlingstein, P., Luo, Y., and Wang, S.: Forest annual carbon cost: a global-scale analysis of autotrophic respiration, Ecology, 91, 652-661, 2010.

Pollock, S. L. and Payette, S.: Stability in the patterns of long-term development and growth of the Canadian spruce-moss forest, J. Biogeogr, 37, 1684-1697, 2010.

Raulier, F., Bernier, P. Y., and Ung, C. H.: Modeling the influence of temperature on monthly gross primary productivity of sugar maple stands, Tree Physiol., 20, 333-345, 2000.

Rossi, S., Deslauriers, A., Anfodillo, T., and Carrer, M.: Agedependent xylogenesis in timberline conifers, New Phytol., 177, 199-208, 2008.

Rudolph, T. D. and Laidley, P. R.: Jack pine (Pinus banksiana Lamb.), edited by: Burns, R. M. and Honkala, B. H., Silvics of North America, vol. 1. Conifers. USDA For. Serv. Handb. 654, 280-290, 1990.

Ryan, M. G., Phillips, N., and Bond, B. J.: The hydraulic limitation hypothesis revisited, Plant Cell Environ, 29, 367-381, 2006.

Ryan, M. G.: A simple method for estimating gross carbon budgets for vegetation in forest ecosystems, Tree Physiol., 9, 255-266, 1991.

Salford Systems: MARS v2.0, Salford Systems, San Diego, Calif, 2001.

Saucier, J.-P., Bergeron, J.-F., Grondin, P., and Robitaille, A.: Les régions écologiques du Québec (3e version): un des éléments du système hiérarchique de classification écologique du territoire mis au point par le ministère des Ressources naturelles du Québec. L'Aubelle, 124, S1-S12, 1998.

Schwalm, C. R., Williams, C. A., Schaefer, K., Anderson, R., Arain, M. A., Baker, I. Barr, A., Black, T. A., Chen, G., Chen, J. M., Ciais, P., Davis, K. J., Desai, A., Dietze, M., Dragoni, D., Fischer, M. L., Flanagan, L. B., Grant, R., Gu, L., Hollinger, D., Izaurralde, R. C., Kucharik, C., Lafleur, P., Law, B. E., Longhui, L., Li, Z., Liu, S., Lokupitiya, E., Luo, Y., Ma, S., Margolis, H., Matamala, R., McCaughey, H., Monson, R. K., Oechel, W. C., Peng, C., Poulter, B., Price, D. T., Riciutto, D. M., Riley, W., Sahoo, A. K., Sprintsin, M., Sun, J., Tian, H., Tonitto, C., Verbeeck, H. and Verma, S. B.: A model-data intercomparison of $\mathrm{CO}_{2}$ exchange across North America: Results from the North American Carbon Program site synthesis, J. Geophys. Res., 115, G00H05, doi:10.1029/2009JG001229, 2010.
Sullivan J. H., Bovard B. D., and Middleton E. M.: Variability in leaf-level $\mathrm{CO}_{2}$ and water fluxes in Pinus banksiana and Picea mariana in Saskatchewan, Tree Physiol., 17, 553-561, 1997.

Szeicz, J. M. and MacDonald, G. M.: Age dependent tree-ring growth response of subarctic white spruce to climate, Can. J. For. Res., 24, 120-132, 1994.

ter Braak, C. J. F. and Smilauer, P.: Canoco Reference manual and user's guide to Canoco for Windows: software for canonical community ordination (version 4). Microcomputer Power, Ithaca, NY, USA, 1998.

ter Braak, C. J. F.: Canonical community ordination. Part I: Basic theory and linear methods, Ecoscience, 1, 127-140, 1994.

ter Braak, C. J. F. and Prentice, I. C.: A theory of gradient analysis, Adv. Ecol. Res., 18, 271-317, 1988.

Vieira, J., Campelo, F., and Nabais, C.: Age-dependent response of tree-ring growth and intra-annual density fluctuations of Pinus pinaster to Mediterranean climate, Trees, 23, 257-265, 2009.

Viereck, L. A. and Johnston, W. F.: Picea mariana (Mill.) B. S. P., edited by: Burns, R. M. and Honkala, B. H.: Silvics of North America, Vol. 1, Conifers. U.S.D.A. Forest Service Agriculture Handbook 654, Washington, DC, 1990.

Wang, X., Piao, S., Ciais, P., Li, J., Friedlingstein, P., Koven, C., and Chen, A.: Spring temperature change and its implication in the change of vegetation growth in North America from 1982 to 2006, Proc. Natl. Acad. Sci. USA, 108, 1240-1245, 2011.

Yamaguchi, D. K.: A simple method for cross-dating increment cores from living trees, Can. J. For. Res., 21, 414-416, 1991.

Yue, S., Pilon, P., Phinney, B., and Cavadias, G.: The influence of autocorrelation on the ability to detect trend in hydrological series. Hydrol. Process., 16, 1807-1829, 2002.

Zaehle, S., Sitch, S., Prentice, I. C., Liski, J., Cramer, W., Erhard, M., Hickler, T., Smith, B.: The importance of age-related decline in forest NPP for modeling regional carbon balances, Ecol. Appl., 16, 1555-1574, 2006.

Zhang, K., Kimball, J. S., Hogg, E. H., Zhao, M., Oechel, W. C., Cassano, J. J., and Running, S. W.: Satellite-based model detection of recent climate-driven changes in northern highlatitude vegetation productivity, J. Geophys. Res., 113, G03033, doi:10.1029/2007JG000621, 2008. 